\title{
Sobre la insostenible pretensión de la existencia de un «derecho de autodeterminación» para separarse de España al amparo del Pacto Internacional de los Derechos Civiles y Políticos
}

\author{
On the dismissible claim of the existence of a «Right to \\ self determination » to secede from Spain invoking \\ the International Covenant on Civil and Political Rights
}

\author{
Carlos Ruiz Miguel \\ Catedrático de Derecho Constitucional \\ Universidad de Santiago de Compostela \\ carlos.ruiz@usc.es
}

RECIBIDO EL 15 DE ENERO DE 2019 / ACEPTADO EL 3 DE FEBRERO DE 2019

\begin{abstract}
Resumen: Resumen: Este artículo analiza el problema de si es posible invocar el derecho de autodeterminación, consagrado en el Pacto Internacional de los Derechos Civiles y Políticos (PIDCP), para legitimar la secesión de España de una de sus regiones. Partiendo de un breve análisis del proceso que ha llevado a la consagración del derecho de autodeterminación en el Derecho Internacional Público, se examina cuál es el estatuto jurídico del PIDCP en el ordenamiento español, tras lo que se recuerda que los intentos de amparar una pretensión separatista en el PIDCP no han sido acogidos en el Derecho interno como tampoco han sido avalados por la doctrina del Comité de Derecho Humanos de Naciones Unidas.
\end{abstract}

Palabras clave: Derecho de autodeterminación, soberanía, Constitución, sistema de fuentes, secesión.

\begin{abstract}
This article deals with the question if the right to self-determination, enshrined in the International Covenant for Civil and Political Rights (ICCPR), might be invoked to defend the secession of one of the Spanish regions. Beginning with reminder of the process that lead to the recognition of a right to self-determination in Public International Law, this contribution analyses what is the legal status of ICCPR in the Spanish legal order and then recalls the failure of the attempts to introduce in the Spanish domestic legal order a secessionist claim based on the ICCPR and that the doctrine of the United Nations Human Rights Committee did not support such interpretation.
\end{abstract}

Keywords: Right to self-determination, sovereignty, Constitution, sources of law, secession.

Sumario: I. BREVE REFERENCIAA LA CONSAGRACIÓN INTERNACIONAL DE LA «AUTODETERMINACIÓN DE LOS PUEBLOS»COMO DERECHO. II. EL ESTATUTO JURÍDICO DEL PACTO INTERNACIONAL DE LOS DERECHOS CIVILES Y POLÍTICOS EN ESPAÑA. III. LA PRETENSIÓN DE UN DERECHO DE AUTODETERMINACIÓN PARA SEPARARSE DE ESPAÑA AL AMPARO DEL PACTO INTERNACIONAL DE LOS DERECHOS CIVILES Y POLITICOS. IV. ANÁLISIS DE LA DOCTRINA DEL COMITÉ DE DERECHOS HUMANOS. V. CONCLUSIÓN.

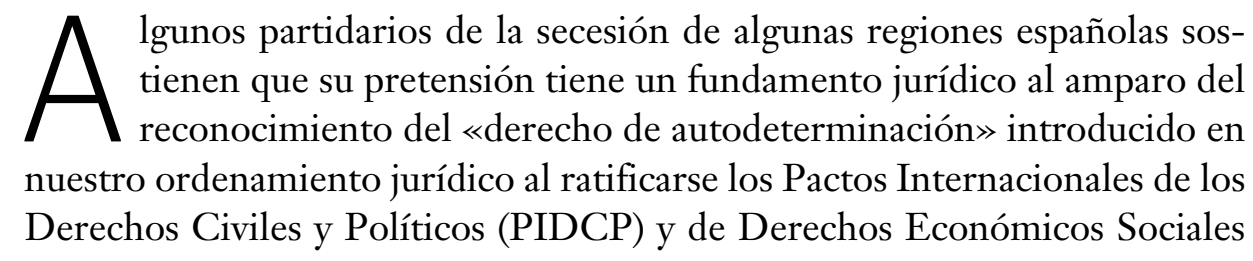


y Culturales. En este trabajo, tras una breve referencia a la consagración de la «autodeterminación» como un «derecho» internacionalmente reconocido (I) se documentará la pretensión de que partes de España puedan invocar el «derecho de autodeterminación» (II), se aclara primero cuál es el status del PIDCP en nuestro sistema (III) tras lo cual se analiza la doctrina y la práctica del Comité de Derechos Humanos (IV) respecto a España, para concluir que esa pretensión es jurídicamente infundada $(\mathrm{V})$.

\section{BREVE REFERENCIA A LA CONSAGRACIÓN INTERNACIONAL DE LA «AUTODETERMINACIÓN DE LOS PUEBLOS» COMO DERECHO}

I.1. La «autodeterminación» (o libre determinación) fue incluida como un «principio» en la Carta de las Naciones Unidas de 1945, pero será en 1960 cuando será proclamada como un «derecho», afirmación reiterada en los Pactos Internacionales de 1966. La Organización de las Naciones Unidas se basa en el respeto del principio del «respeto» a la «libre determinación de los pueblos» para así «fomentar entre las naciones las relaciones de amistad» (art. 1.2 de la Carta de las Naciones Unidas). Ahora bien, también se propone «tomar medidas eficaces» para «suprimir actos de agresión». Esto significa que la «libre determinación» o autodeterminación, de los pueblos aparece configurada en la Carta de Naciones Unidas como una norma de Derecho objetivo y no como un derecho subjetivo.

Sin embargo, quince años después de adoptada la Carta, la resolución 1514 estableció que «todos los pueblos tienen el derecho de libre determinación» y que «en virtud de este derecho los pueblos determinan libremente su condición política». Por consiguiente, la autodeterminación quedaba configurada no ya sólo como un «principio» o norma de Derecho objetivos, sino también como una norma de derecho subjetivo ${ }^{1}$. El hecho, no obstante, es que aunque se formulara como un «derecho», el que ello se hiciera a través de una resolución de la Asamblea General suscitaba dudas acerca de su imperatividad. Esta es una de las razones por las que, para garantizar su plena normatividad se decidió incorporarla a sendos tratados internacionales elaborados bajo los auspicios de Naciones Unidas: el Pacto Internacional de Derechos Civiles y Políticos (PIDCP) y el Pac-

1 A/RES/1514 (XV), de 14 de diciembre de 1960. 
to Internacional de Derechos Económicos, Sociales y Culturales (PIDESC)2 . En todo caso, años después de haber sido aprobado el «derecho» a la autodeterminación en la resolución 1514 de la Asamblea General, el Tribunal Internacional de Justicia lo ha calificado como una norma imperativa o de «ius cogens» ${ }^{3}$.

I.2. Como es notorio una de las cuestiones esenciales sobre esta cuestión es la de quienes son los titulares de los que se predica ese «derecho a la autodeterminación» ${ }^{4}$.

En primer lugar, está claro que todos los «Estados» eran considerados como «pueblos» cuya «auto-determinación» era proclamada en la Carta en el artículo 1.2 de la Carta de las Naciones Unidas. Por tanto, el «principio» de la autodeterminación se predica, indiscutiblemente, de los «pueblos» de los «Estados» miembros de la ONU. Está claro que cuando hablamos de los pueblos que conforman Estados de la comunidad internacional, su autodeterminación nace de su misma existencia política y no es fruto de una atribución por otro ente externo.

En segundo lugar, quedó claro tras la aprobación de la resolución 1514 que el «derecho» a la «autodeterminación» se atribuía a los «pueblos coloniales». La identificación de quienes son estos pueblos la hace la Asamblea General de Naciones Unidas a través del «Comité Especial» que creó para examinar la aplicación de la «Declaración sobre la concesión de independencia a los países y pueblos coloniales» compuesto inicialmente por 17 miembros $^{5}$ y que fue ampliado a 24 miembros en 1962 («Comité de los 24») ${ }^{6}$. Así

2 El artículo 1 común al Pacto Internacional de Derechos Civiles y Políticos y al Pacto Internacional de Derechos Económicos, Sociales y Culturales, ambos de 19 de diciembre de 1966, dice:

$\ll 1$. Todos los pueblos tienen el derecho de libre determinación. En virtud de este derecho establecen libremente su condición política y proveen asimismo a su desarrollo económico, social y cultural.

2. Para el logro de sus fines, todos los pueblos pueden disponer libremente de sus riquezas y recursos naturales, sin perjuicio de las obligaciones que derivan de la cooperación económica internacional basada en el principio del beneficio recíproco, así como del derecho internacional. En ningún caso podrá privarse a un pueblo de sus propios medios de subsistencia.

3. Los Estados Partes en el presente Pacto, incluso los que tienen la responsabilidad de administrar territorios no autónomos y territorios en fideicomiso, promoverán el ejercicio del derecho de libre determinación, y respetarán este derecho de conformidad con las disposiciones de la Carta de las Naciones Unidas.»

3 East Timor (Portugal v. Australia), Judgment, I.C.7, Reports 1995, p. 90 (para. 29).

4 Sobre esta cuestión, cfr. RuIz MiguEL, C., «El principio y derecho de autodeterminación y el pueblo del Sahara Occidental», Anuario Español de Derecho Internacional, vol. 35, 2015, p. 267 ss. (pp. 277-282).

5 A/RES/1654 (XVI), 27 noviembre 1961; A/RES/1700 (XVI), 19 diciembre 1961.

6 A/RES/1810 (XVII), 17 diciembre 1962. 
pues, la Asamblea General puede decidir incluir en la lista a un determinado territorio como «no autónomo» y calificarlo como un «pueblo» con un «derecho» a la «auto-determinación». E igualmente, el Consejo de Seguridad puede calificar a un determinado territorio como un «pueblo» legitimado para la «auto-determinación» En consecuencia, cuando la Asamblea General o el Consejo Seguridad se refieren nominatim a un determinado pueblo no hay duda sobre el reconocimiento internacional de tal «pueblo». En este caso, se trata de «pueblos» que aún no están reconocidos como «Estados» o lo están de modo parcial porque su existencia política está impedida u obstaculizada. Aquí la existencia política de estos pueblos, que no puede afirmarse por su propio poder, es algo reconocido por la comunidad internacional. Como el Derecho internacional prohíbe el uso de la fuerza, no reconoce la privación a un pueblo (el «pueblo colonial») de su soberanía mediante el uso de la fuerza.

En tercer lugar, la Asamblea General de las Naciones Unidas aprobó en 2007 una resolución conteniendo la «Declaración de las Naciones Unidas sobre los derechos de los pueblos indígenas $\rangle^{7}$ que introduce algunos matices en relación a esta cuestión. Esta declaración considera que los «pueblos indígenas» son «pueblos» y que, precisamente por ser tales, tienen «derecho a la libre determinación»... pero atribuyéndoles un «derecho» con un contenido distinto al de los demás «pueblos» (pueblos de los Estados y pueblos coloniales) pues ese derecho NO ampara la pretensión de separación o independencia ${ }^{8}$.

I.3. Fuera del marco del «Estado», de los «pueblos coloniales» y de los «pueblos indígenas» está claro que el Derecho Internacional no parece aceptar, al menos hasta el momento, a ningún «pueblo» con un «derecho» de «autodeterminación» ${ }^{9}$, por más que les pese a los autores que han planteado la posibilidad en abstracto de que exista un «cuarto titular» del derecho de autodeterminación aparte de los «Estados»y los «pueblos coloniales», en la línea

7 A/RES/61/295, 10 de diciembre de 2007.

8 Artículo 4

«Los pueblos indígenas, en ejercicio de su derecho a la libre determinación, tienen derecho a la autonomía o al autogobierno en las cuestiones relacionadas con sus asuntos internos y locales, así como a disponer de medios para financiar sus funciones autónomas».

9 CORTEN, O., «A propos d'un désormais 'classique': Le droit à l'autodetermination en dehors des situations de décolonisation, de Théodore Christakis», Révue Belge de Droit International, XXXII, 1999, 1 , pp. 329-349; GutiÉRreZ EsPaDA, C.; BerMejo GarCía, R., «El derecho de libre determinación de los pueblos no coloniales a la luz del Derecho Internacional», en J. J. Solozábal Echevarría (coord.), La autodeterminación a debate, Madrid, Fundación Pablo Iglesias, 2014, pp. 93-118. 
sugerida por Cassese para quien la resolución 2625 contiene una «cláusula de salvaguardia» (saving clause) de la auto-determinación interna, de suerte que el respeto a la misma pudiera quedar garantizado con la auto-determinación externa ${ }^{10}$. Para ello dan una interpretación, a mi juicio, forzada de la resolución 2625 (XXV) que establece (cursiva mía):

«Ninguna de las disposiciones de los párrafos precedentes se entenderá en el sentido de que autoriza o fomenta cualquier acción encaminada a quebrantar o menospreciar, total o parcialmente, la integridad territorial de Estados soberanos e independientes que se conduzcan de conformidad con el principio de la igualdad de derechos y de la libre determinación de los pueblos antes descritos y estén, por tanto dotados de un gobierno que represente a la totalidad del pueblo perteneciente al territorio, sin distinción por motivo de raza, credo o color».

Si la resolución 2625 exige que haya autodeterminación de todo el pueblo, la falta de una autodeterminación interna de esa «totalidad del pueblo» no puede solucionarse con una partición del mismo, sino con la consecución del objetivo de que esa «totalidad del pueblo» consiga un gobierno representativo.

Pero que el Derecho Internacional no reconoce este «cuarto titular» del derecho a la autodeterminación es indiscutible a la luz de la Opinión Consultiva del Tribunal Internacional de Justicia en el caso de Kosovo, donde dijo:

«Si, fuera del contexto de los territorios no autónomos y pueblos sometidos a subyugación, dominación y explotación extranjeras, el Derecho Internacional de la auto-determinación confiere a parte de la población de un Estado existente un derecho a separarse de ese Estado es, sin embargo, un asunto sobre el que se han expresado opiniones radicalmente diferentes por los que han tomado parte en este procedimiento y han expresado una posición sobre la cuestión. Diferencias similares existieron respecto a si el Derecho Internacional reconoce un derecho de «secesión como garantía» y, de ser así, en qué circunstancias. También hubo una aguda divergencia de opiniones acerca de si las circunstancias que algunos participantes mantuvieron que darían lugar a un derecho de «secesión como garantía» se hallaban presentes en Kosovo» ${ }^{11}$.

10 CASSESE, A., Self-determination of peoples. A legal reappraisal, Cambridge (UK), Cambridge University Press, 1995 , p. 109 ss.

11 Accordance with International Law of the Unilateral Declaration of Independence in Respect of Kosovo, Advisory Opinion, I.C.J. Reports 2010, para 82: «Whether, outside the context of non-self-governing territories and peoples subject to alien subjugation, domination and exploitation, the international law 
La opinión consultiva del TIJ en el asunto de Kosovo es especialmente interesante porque en las actuaciones se llegó a defender la tesis de que la resolución 2625 (XXV) contenía la «cláusula de salvaguardia» según la idea sugerida por Cassese, sin que esta tesis fuera acogida por el Tribunal.

I.4. A la luz de lo expuesto resulta meridianamente claro que el «Preámbulo» de la llamada «Ley» catalana de «Referéndum de autodeterminación ${ }^{12}$ miente de forma descarada cuando dice:

«En dictámenes recientes (sic), el Tribunal Internacional de Justicia afirma que, durante la segunda mitad del siglo XX ha habido casos de nuevos estados que han ejercido el derecho a la autodeterminación (sic) sin que el ejercicio de este derecho a decidir estuviera motivado por el fin del imperialismo. El Tribunal constata que el derecho a decidir (sic) de los pueblos ha evolucionado y que en contra de esta evolución no ha surgido ninguna norma ni costumbre en el orden internacional que prohíba estas nuevas prácticas. La única limitación a la legitimidad del ejercicio del derecho a decidir (sic) que el Tribunal considera vigente es el recurso ilícito de la fuerza o de otras violaciones graves de normas de derecho internacional».

Por lo que ahora respecta, este «Preámbulo» contiene dos graves falsedades. En primer lugar, atribuye al dictamen del TIJ afirmaciones sobre el supuesto «derecho a decidir», pese a que en ningún momento utiliza esa expresión. Ade-

of self-determination confers upon part of the population of an existing State a right to separate from that State is, however, a subject on which radically different views were expressed by those taking part in the proceedings and expressing a position on the question. Similar differences existed regarding whether international law provides for a right of «remedial secession» and, if so, in what circumstances. There was also a sharp difference of views as to whether the circumstances which some participants maintained would give rise to a right of «remedial secession» were actually present in Kosovo».

No ha alterado esta doctrina la Opinión Consultiva sobre el asunto de Chagos de 25 de febrero de 2019. Cfr. Legal consequences of the separation of the Chagos archipielago from Mauritius in 1965, Advisory Opinion, I.C.J. Reports 2019, para. 144 ( $\ll$ The Court will have to determine the nature, content and scope of the right to self-determination applicable to the process of decolonization of Mauritius, a non-self-governing territory recognized as such, from 1946 onwards, both in United Nations practice and by the administering Power itself. The Court is conscious that the right to self-determination, as a fundamental human right, has a broad scope of application. However, to answer the question put to it by the General Assembly, the Court will confine itself, in this Advisory Opinion, to analyzing the right to self-determination in the context of decolonization»). Como hemos visto ya, legalmente también está reconocido el derecho de autodeterminación de los "pueblos indígenas" y de los pueblos de los Estados.

12 «Ley» 19/2017, de 6 de septiembre, del referéndum de autodeterminación, en Diari Oficial de la Generalitat de Catalunya, de 7 de septiembre de 2017. 
más, en segundo lugar, y por lo que respecta al «derecho a la autodeterminación» el TIJ tampoco dice lo que el «preámbulo» de la «ley» catalana le atribuye pues sólo dice que sobre esta cuestión hay «diferentes opiniones» pero EN NINGÚN MOMENTO afirma que en estos otros casos exista un «derecho de autodeterminación». Como veremos más adelante, estas no son las únicas inexactitudes contenidas en la «ley» catalana de referéndum de autodeterminación.

\section{LA PRETENSIÓN DE UN DERECHO DE AUTODETERMINACIÓN PARA PARTES DE ESPAÑA AL AMPARO DEL PACTO INTERNACIONAL DE LOS DERECHOS CIVILES Y POLÍTICOS}

II.1. Parece difícil discutir que la pretensión de que una parte de España pueda tener un «derecho de autodeterminación» no se encuentra en la Constitución. En los debates sobre la redacción de la Constitución de 1978 se presentaron cuatro enmiendas (dos de Letamendía en el Congreso y dos de Bandrés en el Senado) para introducir este «derecho», todas las cuales invocaban el PIDCP.

La primera enmienda, del diputado Francisco Letamendía Belzunze ${ }^{13}$, presentada ante la Comisión de Asuntos Constitucionales y Libertades Públicas decía que: «La Constitución se fundamenta en la plurinacionalidad del Estado español. La solidaridad entre sus pueblos. El derecho a la autonomía de las regiones y naciones que lo integran. Y el derecho a la autodeterminación de estas últimas» (mantengo la deficiente puntuación original). Entre las razones alegadas, el diputado Letamendía invocó el supuesto reconocimiento que de tal derecho hacía el PIDCP ratificado por España ${ }^{14}$. La enmienda no fue votada pues el diputado Letamendía renunció a su defensa y adujo que había presentado otra enmienda sobre la autodeterminación ${ }^{15}$. En efecto, más adelante, el diputado Letamendía presentó

13 Enmienda ${ }^{\circ} 64$.

14 Cortes. Diario de Sesiones del Congreso de los Diputados, n. ${ }^{\circ}$ 66, 12 de mayo de 1978, p. 2265 («Por lo visto, lo que para pueblos que no están en el Estado español es un perfecto derecho, para aquellos pueblos que están dentro de ese Estado no lo es. Para nosotros no cabe más explicación que ésta, que se están introduciendo criterios de raza o de color de piel para afirmar el derecho para unos pueblos y negarlo para otros. Incluso puedo hablar de incoherencia de la Unión de Centro Democrático, dado que este Partido es el Partido del Gobierno, y que el Gobierno ha ratificado un Pacto Internacional, el Pacto Internacional de Derechos Civiles y Políticos, en el cual, en el artículo 1.» se afirma el derecho de los pueblos a su libre determinación»).

15 Cortes. Diario de Sesiones del Congreso de los Diputados, n. ${ }^{\circ}$ 66, 12 de mayo de 1978, p. 2319. 
ante el Pleno del Congreso de los Diputados una enmienda para introducir un Título VIII bis con la rúbrica «Del ejercicio del derecho de autodeterminación» cuyo propuesto artículo 149 bis contenía una invocación explícita al PIDCP: «El derecho a la autodeterminación de los pueblos del Estado español supone, de acuerdo con el Pacto Internacional de Derechos Civiles y Políticos ratificados en su día por aquél, el que los mismos establezcan libremente su condición política, pudiendo en consecuencia optar entre seguir formando Darte del Estado o separarse pacíficamente de éste y constituir un Estado independiente $\gg^{16}$. La enmienda de Letamendía fue rechazada por 5 votos a favor, 268 en contra -incluidos los de los diputados del PNV-y 11 abstenciones, de las que nueve, corresponden a diputados de la Minoría Catalana ${ }^{17}$.

En el Senado, Juan María Bandrés Molet presentó dos enmiendas para incluir este «derecho» en el texto constitucional que fueron discutidas, y rechazadas, en la Comisión de Constitución. La primera enmienda, al artículo 2 del proyecto de Constitución tenía este tenor: «La Constitución se fundamenta en la plurinacionalidad del Estado español, la solidaridad entre los pueblos, el derecho a la autonomía de las regiones y naciones que lo integran y el derecho a la autodeterminación de estas últimas» ${ }^{18}$. La fundamentación de la enmienda se basaba, entre otras razones, en el Pacto Internacional de los Derechos Civiles y Políticos ${ }^{19}$. Votada la enmienda en la Comisión de Constitución fue rechazada por 21 votos en contra y 3 abstenciones ${ }^{20}$. La segunda enmienda ${ }^{21}$, pretendiendo introducir un Título VIII bis con la rúbrica «Del ejercicio del derecho de autodeterminación» fue defendida apelando nuevamente, entre otros motivos, al Pacto Internacional de los Derechos Civiles y Políticos ${ }^{22}$ y también fue rechazada por 21 votos en contra y 3 abstenciones ${ }^{23}$.

16 Cortes. Diario de Sesiones del Congreso de los Diputados, n. ${ }^{\circ}$ 116, 21 de julio de 1978, p. 4564.

17 Cortes. Diario de Sesiones del Congreso de los Diputados, n. ${ }^{\circ}$ 116, 21 de julio de 1978, p. 4567.

18 Enmienda n. ${ }^{\circ} 290$.

19 Cortes. Diario de Sesiones del Senado, n. ${ }^{\circ}$ 40, 19 de agosto de 1978, p. 1601 («El Pacto Internacional de los Derechos Civiles y Políticos no hace distingos entre pueblos colonizados o no, en su artículo primero»).

20 Cortes. Diario de Sesiones del Senado, n. ${ }^{\circ}$ 40, 19 de agosto de 1978, p. 1641.

21 Enmienda $\mathrm{n}^{\circ} 315$.

22 Cortes. Diario de Sesiones del Senado, n. ${ }^{\circ}$ 54, 13 de septiembre de 1978, p. 2696 («El derecho de autodeterminación de los pueblos, conforme al Pacto Internacional de los Derechos Civiles y Políticos de las Naciones Unidas, firmado y ratificado por el Estado español, es, como se sabe, el derecho de los pueblos a establecer libremente su condición política, pudiendo, en consecuencia, optar entre seguir formando parte del Estado o separarse pacíficamente de éste y constituir un Estado independiente»).

23 Cortes. Diario de Sesiones del Senado, n. ${ }^{\circ}$ 54, 13 de septiembre de 1978, p. 2700. 
Por tanto, es un dato que nadie puede negar que los redactores de la Constitución no reconocieron un «derecho de autodeterminación» para partes de España y que la pretensión de que el PIDCP lo avalaba fue repetida, y abrumadoramente, rechazada.

II.2. A partir de 1989, los parlamentos regionales catalán y vasco han aprobado diversas «proposiciones no de ley» $\mathrm{O}$ «resoluciones» donde han pretendido atribuirse el «derecho de autodeterminación». Si bien esta pretensión no apelaba explícitamente al PIDCP, en el caso vasco se hacía en unos términos que evocaban claramente el artículo 1 del PIDCP. El 12 de diciembre de 1989 el Parlamento regional catalán aprobó una Resolución cuyo apartado 2 decía que:

«(El Parlamento de Cataluña) Manifiesta que el acatamiento del marco institucional vigente, resultado del proceso de transición política de la dictadura a la democracia, no significa la renuncia del pueblo catalán a su derecho a la autodeterminación, tal como establecen los principios generales de los organismos internacionales y se deduce implícitamente del Preámbulo del Estatuto de autonomía de Cataluña de 1979» ${ }^{24}$.

Meses después, el 26 de febrero de 1990, el parlamento regional vasco aprobó otra resolución atribuyéndose el derecho de autodeterminación proclamando «Que el Pueblo Vasco tiene derecho a la autodeterminación. Este derecho reside en la potestad de sus ciudadanos para decidir libre y democráticamente su estatus político, económico, social y cultural, bien dotándose de un marco político propio o compartiendo, en todo o en parte, su soberanía con otros pueblos» ${ }^{25}$.

Mientras el parlamento regional vasco no se ha prodigado desde entonces en declaraciones similares (sólo volvió a proclamar ese supuesto «derecho de autodeterminación» en 201426), el parlamento regional catalán sí lo ha

24 Resolución 98/III, de 12 de diciembre de 1989, sobre el derecho a la autodeterminación de la nación catalana, en Butlletí Oficial del Parlament de Catalunya, $\mathrm{n}^{\circ}$ 120/3 (18-XII-1989), p. 7791-7792.

25 Boletín Oficial del Parlamento Vasco, n. ${ }^{\circ}$ B-IV-134-135(d) (26-II-1990).

26 Proposición no de Ley 100/2014, relativa al derecho de autodeterminación de Euskal Herria. El texto decía, escuetamente que «El Parlamento Vasco ratifica y proclama que Euskal Herria tiene derecho a la autodeterminación y que este derecho reside en la potestad de sus ciudadanos para decidir libre y democráticamente su estatus político, económico, social y cultural, bien dotándose de un marco político propio, bien compartiendo, en todo o en parte, su soberanía con otros pueblos».

En el debate el diputado de EH Bildu apeló al PIDCP y al PIDESC aunque en el texto de la proposición no de ley no haya referencias a estos Pactos (Cfr. Parlamento vasco. Diario de sesiones, $\mathrm{X}$ legislatura, $\mathrm{n}^{\circ}$ 80, 29 de mayo de 2014, p. 97). La proposición no de ley se aprobó por 48 votos a favor y 27 en contra (ibid., p. 106). 
hecho. Así, ha reiterado ese supuesto derecho a la autodeterminación en las «resoluciones» de 1 de octubre de $1998^{27}$, de 3 de marzo de $2010^{28}$, de 10 de marzo de $2011^{29}, 27$ de septiembre de $2012^{30}, 6$ de octubre de $2016^{31}, 6$ de julio de $2018^{32}$ y 24 de enero de $2019^{33}$. Sin embargo, la «resolución» que aprueba

27 Resolución 679/V de 1 de octubre de 1998, sobre la orientación política general del Consejo Ejecutivo, Butlletí Oficial del Parlament de Catalunya n 327/5 (13-X-1998), p. 25974 (1. El Parlamento de Cataluña, en el marco de la celebración del cincuenta aniversario de la Declaración universal de los derechos humanos, ratifica una vez más el derecho del pueblo catalán a determinar libremente su futuro como pueblo, en paz, democracia y solidaridad».).

28 Resolución 631/VIII, de 3 de marzo de 2010, de la la Comisión de Asuntos institucionales del Parlamento catalán, Butlletí Oficial del Parlament de Catalunya $\mathrm{n}^{\circ}$ 657/08 (22-III-2010), p. 19 («El Parlamento de Cataluña: 1.Ratifica la vigencia de la Resolución 98/III, sobre el derecho a la autodeterminación de la nación catalana, adoptada el 12 de diciembre del 1989, y de la Resolución 679/V, adoptada el1 de octubre del 1998, de ratificación de la anterior»). Es interesante advertir que la «ley» del «referéndum de autodeterminación» en su «Preámbulo» cita inexactamente esta resolución como «Resolución 631/VIII del Parlamento de Cataluña, sobre el derecho a la autodeterminación y sobre el reconocimiento de las consultas populares sobre la independencia, adoptada el $10 \mathrm{de}$ marzo de 2010» confundiendo la fecha «10 de marzo» con la de la Moción 6/IX a la que no cita el mencionado «Preámbulo».

29 Moción 6/IX, de 10 de marzo de 2011, sobre el derecho a la autodeterminación del pueblo de Cataluña y sobre el derecho de la sociedad a expresarse por medio de consultas populares, Butlletí Oficial del Parlament de Catalunya n ${ }^{\circ}$ 36/09 (14-III-2011), p. 6-7. ( «El Parlamento de Cataluña: 1.Ratifica la vigencia de la Resolución 98/III, sobre el derecho a la autodeterminación de la nación catalana, adoptada el 12 de diciembre del 1989, y de la Resolución 679/V, adoptada el1 de octubre del 1998, de ratificación de la anterior»).

30 Resolución 742/IX, de 27 de septiembre de 2012, sobre la orientación política general del Gobierno, Butlletí Oficial del Parlament de Catalunya no 390/09 (2-X-2012), p. 3 (II.4. [...] El Parlamento de Cataluña proclama solemnemente, tal como ya ba becho en otras ocasiones transcendentales, el derecho imprescriptible e inalienable de Cataluña a la autodeterminación, como expresión democrática de su soberanía como nación»).

31 Resolución 306/XI del Parlament de Catalunya, sobre l'orientació política general del Govern, de 6 de octubre de 2016, en Butlletí Oficial del Parlament de Catalunya n ${ }^{\circ}$ 390/09 (2-X-2012), p. 3 («El Parlamento de Cataluña afirma, como ya ha hecho en otras ocasiones, el derecho imprescriptible e inalienable de Cataluña a la autodeterminación»).

32 Moción 5/XII, de 5 de julio de 2018, sobre la normativa del Parlamento anulada y suspendida por el Tribunal Constitucional, Butlletí Oficial del Parlament de Catalunya $\mathrm{n}^{\circ}$ 121/12 (9-VII2018), p. 16-17 ( $\ll 3$. El Parlament de Catalunya ha expressat en moltes ocasions la defensa del dret a decidir i de l'autode-terminació $i$, en conseqüència, com a dipositari de la sobirania del poble de Catalunya i amb fidelitat a la seva voluntat, reitera el compromís d'assolir aquests objectius polítics per vies democràtiques i no violentes.»). Este apartado fue anulado por la STC 136/2018, de 13 de diciembre (ponente: Enríquez).

33 Moción 42/XII, de 24 de enero de 2019, sobre el balance del año transcurrido desde las elecciones de 21 de diciembre de 2016 y la vulneración (sic) de los derechos civiles y políticos, Butlletí Oficial del Parlament de Catalunya n ${ }^{\circ}$ 246/12 (28-I-2019), p. 8-9 («6. El Parlament de Catalunya insisteix en la necessitat de construir una solució política basada necessàriament en la democràcia i l'exercici del dret a l'autodeterminació, i exigeix la fi de la via repressiva de l'Estat espanyol.»). 
la «Declaración de soberanía y el derecho a decidir del pueblo de Cataluña» no contiene ninguna mención explícita al «derecho de autodeterminación» ${ }^{34}$.

Finalmente, han intentado introducir ese «derecho» en la pretendida «ley» del «referéndum de autodeterminación» ${ }^{35}$, núcleo fundamental del golpe de Estado catalanista de septiembre-octubre de $2017^{36}$, y que fue anulada por el Tribunal Constitucional ${ }^{37}$. Esta «ley» es el primer texto del parlamento regional catalán que invoca el «derecho de autodeterminación» haciendo referencia al PIDCP y al PIDESC. Es esta una idea que, en la línea de las fracasadas enmiendas de Letamendía y Bandrés en la discusión de la Constitución de 1978, han defendido algunos autores estimando esos convenios internacionales como fuente del derecho a la autodeterminación independientemente de lo que dijera la Constitución ${ }^{38}$.

El «Preámbulo» de la «Ley» de referéndum de autodeterminación dice:

«I. Los pactos sobre Derechos Civiles y Políticos y sobre Derechos Económicos, Sociales y Culturales, aprobados por la Asamblea General de las Naciones Unidas el 19 de diciembre de 1966, ratificados y en vigor en el Reino de España desde 1977 -publicados en el BOE de 30 de abril de 1977reconocen el derecho de los pueblos a la autodeterminación como el primero de los derechos humanos. Asimismo, el artículo 1.2 de la Carta de las Naciones Unidas y el Estatuto de la Corte Internacional de Justicia estable-

34 Resolución 5/X del Parlamento de Cataluña por la que se aprueba la Declaración de soberanía y el derecho a decidir del pueblo de Cataluña, en Butlletí Oficial del Parlament de Catalunya $\mathrm{n}^{\mathrm{o}} 13 / 10$ (24-I-2013), p. 3 ss. Esta resolución fue impugnada ante el Tribunal Constitucional que la anuló en su STC 42/2014, de 25 de marzo (ponente: Asúa).

Nuevamente, el «Preámbulo» de la «Ley» del «referéndum de autodeterminación» comete un error al decir que esta resolución invocaba el «derecho de autodeterminación». Las palabras del citado «Preámbulo»son: «Más recientemente, la Resolución 5/X del Parlamento de Cataluña, por la que se aprueba la Declaración de soberanía y del derecho a decidir del pueblo de Cataluña y (...), han afirmado el derecho imprescriptible e inalienable de Cataluña a la autodeterminación».

35 «Ley» 19/2017, de 6 de septiembre, del referéndum de autodeterminación, en Diari Oficial de la Generalitat de Catalunya, de 7 de septiembre de 2017.

36 Artículo 3.2 de la «Ley» 19/2017: «Esta Ley establece un régimen jurídico excepcional dirigido a regular y garantizar el referéndum de autodeterminación de Cataluña. Prevalece jerárquicamente sobre todas las normas que puedan entrar en conflicto con la misma, en tanto que regula el ejercicio de un derecho fundamental e inalienable del pueblo de Cataluña».

37 STC 114/2017, de 17 de octubre (ponente: Ollero).

38 Obieta Chalbaud, J. A., El derecho bumano de la autodeterminación de los pueblos, Madrid, Tecnos, 1989, p. 59; VICIANO PASTOR, R., «El derecho de autodeterminación en nuestra reciente vida constitucional: análisis y problemática», Revista de Derecho Político, n 34, 1991, p. 143 ss. (p. 150). 
ce entre sus propósitos fomentar entre las naciones relaciones de amistad basadas en el respeto al principio de la igualdad de derechos y al de la autodeterminación de los pueblos.

La Constitución española de 1978 determina en el artículo 96 que los tratados internacionales ratificados por España forman parte de su ordenamiento interno y, en el artículo 10.2, establece que las normas relativas a los derechos fundamentales y las libertades públicas se interpretarán de acuerdo con los tratados internacionales aplicables en esta materia (...)〉.

Para examinar si esta invocación es pertinente analizaremos el significado del PIDCP (omitimos el caso del PIDESC que es similar) para España tanto en el Derecho Constitucional (III) como en el Derecho Internacional (IV).

\section{EL ESTATUTO JURÍDICO DEL PACTO INTERNACIONAL DE LOS DERECHOS CIVILES Y POLÍTICOS EN ESPAÑA}

El Pacto Internacional de Derechos Civiles y Políticos fue aprobado por la Asamblea General de las Naciones Unidas por resolución 2200 A (XXI), de 16 de diciembre de 1966 y entró en vigor el 23 de marzo de 1976, de conformidad con su artículo 49, cuando hubo sido ratificado por 35 Estados. Apenas unos meses después de que entrara en vigor, ya en los primeros momentos de la transición desde el franquismo a la democracia liberal, el 28 de septiembre de 1976, España lo firmó. Y en un breve lapso de tiempo, el 13 de abril de 1977, el Rey Juan Carlos lo ratificó, siendo depositado el Instrumento de Ratificación el 27 de abril y publicado ${ }^{39}$. El Pacto, por tanto, se ratificó antes de que se constituyeran las Cortes (elegidas el 15 de junio de 1977) que, más tarde, elaboraron la Constitución de 1978 y entró en vigor (el 27 de julio de 1977, tres meses después de su ratificación, en virtud de lo previsto en su artículo 49) cuando ya se habían elegido dichas Cortes pero aún no habían aprobado la Constitución. Por tanto, el Pacto es un instrumento pre-constitucional.

Para analizar los eventuales efectos de una conformidad o disconformidad del PIDCP con la Constitución es importante recordar que aquél es previo ésta. Desde el punto de vista del Derecho Constitucional si fuera cierto que el PIDCP reconoce el derecho a la autodeterminación a partes de España sería indudable que estaría contradiciendo la Constitución, pues el «derecho a la

39 Boletín Oficial del Estado no 103, del 30 de abril de 1977. 
autodeterminación» no es otra cosa que el «derecho» a tener una «soberanía» y el Preámbulo de la Constitución y sus artículos 1.2 y 2 se refieren a una única soberanía que corresponde a todo el pueblo español y no a diversas soberanías de los «pueblos» que conformarían el Estado español. Que sólo existe una soberanía y un único poder constituyente es doctrina que no admite discusión y que ha dejado asentada de modo muy claro el Tribunal Constitucional:

«El imperio de la Constitución como norma suprema (STC 54/1983, de 21 de junio, FJ 2, y, antes aún, STC 16/1982, de 28 de abril, FJ 1), declarado expresamente por su artículo 9.1, trae causa de que la Constitución misma es fruto de la determinación de la Nación soberana por medio de un sujeto unitario, el pueblo español, en el que reside aquella soberanía y del que emanan los poderes del Estado. Se destaca también que la soberanía de la Nación, residenciada en el pueblo español, conlleva necesariamente su unidad (art. 2 $\mathrm{CE}$ ), mediante la que la Nación misma se constituye, al propio tiempo, en Estado social y democrático de derecho. Un Estado único, común para todos y en todo el territorio, sin perjuicio de su articulación compuesta o compleja por obra del reconocimiento constitucional de autonomías territoriales, siendo así el artículo 1.2 CE base de todo nuestro ordenamiento jurídico [STC 259/2015, FJ 4.a); en términos análogos, STC 90/2017, FJ 6 a)]» ${ }^{40}$.

En consecuencia, si el PIDCP atribuyera a partes de España el «derecho» a la «autodeterminación» les estaría atribuyendo una «soberanía» lo que sería contrario a preceptos esenciales de la Constitución (Preámbulo, y artículos 1.2, 2 y 8.1). En el supuesto de que el PIDCP fuera contrario a la Constitución su instrumento de ratificación debería entenderse derogado, en aplicación de lo prevenido en la disposición derogatoria tercera de la Constitución: «Asimismo quedan derogadas cuantas disposiciones se opongan a lo establecido en esta Constitución». Ahora bien, el Tribunal Constitucional al examinar la constitucionalidad de la «ley» de referéndum de autodeterminación (que, como hemos visto, invocaba explícitamente al PIDCP y al PIDESC) declaró que no existía tal incompatibilidad. Merece la pena reproducir las consideraciones que ha hecho el TC a este respecto:

«Es cierto que tanto en el Pacto internacional de derechos civiles y políticos, de 19 de diciembre de 1966, como en el de derechos económicos y sociales, de igual fecha, de los que España es parte, se proclama, y así lo recuerda

40 STC $114 / 2017\left(\mathrm{FJ} \mathrm{5} 5^{\circ}\right.$. 
el preámbulo de esta Ley 19/2017, que «Todos los pueblos tienen el derecho de libre determinación» (art. 1.1 de uno y otro tratado). No lo es menos que diversas resoluciones inequívocas de las Naciones Unidas, en cuyo ámbito se suscribieron aquellos Pactos, han acotado ese derecho, entendido como pretensión de acceso unilateral a la independencia, a los casos de «sujeción de pueblos a una subyugación, dominación y explotación extranjeras». Fuera de ellos «todo intento encaminado a quebrantar total o parcialmente la unidad nacional y la integridad territorial de un país es incompatible con los propósitos y principios de la Carta de las Naciones Unidas», como se afirma en los números 1 y 6 de la Declaración sobre la concesión de la independencia a países y pueblos coloniales, aprobada por Resolución 1514 (XV) de la Asamblea General de las Naciones Unidas el 14 de diciembre de 1960.

Con mayor precisión aún se pronuncia la Declaración 50/6 de Naciones Unidas, cuyo párrafo tercero del punto uno recoge lo siguiente: «Seguir reafirmando el derecho de todos los pueblos a la libre determinación, teniendo en cuenta la situación particular de los pueblos sometidos a dominación colonial o a otras formas de dominación u ocupación extranjeras, y reconociendo el derecho de los pueblos a tomar medidas legítimas, de conformidad con la Carta de las Naciones Unidas, encaminadas a realizar su derecho inalienable a la libre determinación. Nada de lo anterior se entenderá en el sentido de que autoriza o fomenta acción alguna encaminada a quebrantar o menoscabar, total o parcialmente, la integridad territorial o la unidad política de Estados soberanos e independientes que se conduzcan de conformidad con el principio de la igualdad de derechos y de la libre determinación de los pueblos y estén, por tanto, dotados de un gobierno que represente a la totalidad del pueblo perteneciente al territorio, sin distinción alguna»

\section{(...)}

Basta con lo dicho para excluir todo pretendido fundamento en el Derecho internacional de las invocaciones del preámbulo de la Ley 19/2017 a la «autodeterminación» de Cataluña. De tales invocaciones se viene a propugnar el imposible jurídico de que la Constitución misma fuera, en su núcleo esencial, inaplicada o desplazada en atención a unos u otros compromisos internacionales. Sin perjuicio de que tales compromisos no existen en modo alguno con el alcance o contenido que se pretende. No sobrará recordar que el respeto a la «identidad nacional», a las «estructuras fundamentales políticas y constitucionales» y a la «integridad territorial» de los Estados miembros son principios que están expresamente proclamados, y con el más alto rango, en el derecho europeo (art. 4.2 del Tratado de la Unión Europea) $\gg^{41}$.

41 STC 114/2017 (FJ 2.A.b). 
A la vista de este texto parece claro que el Tribunal Constitucional interpreta que ese «derecho de autodeterminación» se predica tanto de los países y pueblos coloniales como de los pueblos de los Estados soberanos e independientes. Es obvio que Cataluña ni está incluida en la lista de Naciones Unidas de los países y pueblos coloniales ${ }^{42}$ ni es un Estado soberano e independiente. Se puede concluir así que para el Tribunal Constitucional el PIDCP no reconoce un «derecho de autodeterminación» a partes de España y por tanto no contradice lo dispuesto en la Constitución Española.

\section{ANÁLISIS DE LA DOCTRINA DEL COMITÉ DE DERECHOS HUMANOS}

Cumple a continuación examinar si la pretensión separatista catalanista de invocar el PIDCP frente a España cuenta con base en el Derecho Internacional. De entrada, independientemente de la consideración del estatuto jurídico del PIDCP en el Derecho Español, desde el punto de vista del Derecho Internacional existe, si no unanimidad sí una abrumadora mayoría de internacionalistas españoles que consideran que la invocación del derecho de autodeterminación carece de sentido para referirlo a Cataluña. Baste recordar, a este respecto la «Declaración sobre la falta de fundamentación en el Derecho Internacional del referéndum de independencia que se pretende celebrar en Cataluña ${ }^{43}$ elaborada por un grupo de profesores ${ }^{44} \mathrm{y}$ suscrita por lo más granado de los internacionalistas españoles y publicada el 19 de septiembre de 2017. Más concretamente, y en referencia al PIDCP y al PIDESC, esta Declaración afirma «Nada en los Pactos Internacionales de 1966, en ningún otro tratado sobre derechos humanos, ni en la jurisprudencia internacional apunta a la consagración de un derecho de las comunidades territoriales infra estatales a pronunciarse sobre la independencia y separación del Estado»

42 La lista se puede ver en el Anexo al documento «Información sobre los Territorios No Autónomos transmitida en virtud del inciso e del Artículo 73 de la Carta de las Naciones Unidas», Informe del Secretario General de 24 de enero de 2018 (A/73/64).

43 El texto se encuentra, amén de en otros lugares, en la Revista española de derecho internacional, vol. 70, n. ${ }^{\circ}$ 1, 2018, pp. 295-298.

44 Paz Andrés Sáenz de Santa María (Universidad de Oviedo), Gregorio Garzón Clariana (Universidad Autónoma de Barcelona), Araceli Mangas Martín (Universidad Complutense de Madrid), Xavier Pons Rafols (Universidad de Barcelona), Antonio Remiro Brotóns (Universidad Autónoma de Madrid), Alejandro del Valle Gálvez (Universidad de Cádiz) y Rafael Arenas García (Universidad Autónoma de Barcelona). 
Pero conviene ir más allá y analizar cuál es la doctrina y la práctica del Comité de Derechos Humanos, el órgano encargado de la interpretación del PIDCP. Hasta el momento, España ha presentado seis informes periódicos.

IV.1. En virtud de lo prevenido en su artículo 40 del PIDCP, y unos meses más tarde del plazo de un año desde que el Pacto entró en vigor en su territorio, España presentó su informe inicial el 1 de septiembre de $1978^{45}$, complementado tras la entrada en vigor de la Constitución ${ }^{46}$. El informe inicial de España fue examinado por el Comité de Derechos Humanos en sus sesiones $141^{\mathrm{a}}, 142^{\mathrm{a}}$ y $143^{\mathrm{a}}$ celebradas los días 20 y 21 de abril de $1979^{47}$. Es decir, el primer informe sobre el cumplimiento del PIDCP por España se aprobó cuando ya se había promulgado la Constitución de 1978. De hecho, las preguntas de los miembros del Comité se refirieron a la Constitución. Por tanto, si hubiera habido alguna incompatibilidad de la Constitución (sus artículos 1.2, 2 y 8.1, especialmente) con el artículo 1 PIDCP se habría advertido por el Comité.

$\mathrm{El}$ informe fue defendido por José María Morenilla Rodríguez el día 20 de abril de 1979. Respecto al art. 1 PIDCP (derecho de autodeterminación), el agente español dijo que la tendencia global del orden jurídico y político español desde la accesión al trono de Juan Carlos I ha sido una continua reforma de los instrumentos jurídicos del régimen anterior con vistas a restaurar la soberanía del pueblo español y a garantizar sus derechos y libertades ${ }^{48}$. Esta afirmación significaba, claramente, que se entendía que el derecho de autodeterminación correspondía al pueblo español.

En los comentarios al informe de España ninguno de los miembros del Comité planteó que el respeto del derecho de autodeterminación exigiera que fuera atribuible a las regiones que forman España para poder separarse. Antes al contrario, las preguntas de los miembros del Comité indicaban todo lo contrario. Así, el profesor noruego Torkel Opsahl precisamente interrogó acerca de si el derecho a la autonomía del artículo 2 de la Constitución permitía impedir la discriminación entre «las nacionalidades y regiones que compo-

45 CCPR/C/4/Add. 1.

46 CCPR/C/4/Add. 3 y CCPR/C/4/Add.5.

47 CCPR/C/SR.141, CCPR/C/SR.142 y CCPR/C/SR.143.

48 «With regard to the specific implementation of each article of the Covenant, be pointed out, in respect of article 1, that the entire trend in the Spanish legal and political order since the accession to the throne of fuan Carlos I in 1975 had been a constant reform of the legal instruments of the previous regime with a view to restoring the sovereignty of the Spanish people and guaranteeing fundamental rights and freedoms» (CCPR/C/SR.141 para. 22). 
nen la nación española ${ }^{49}$. Por su parte, el jurista y diplomático británico Sir Vincent Evans preguntó acerca de qué medidas contemplaba el Estado para asegurar que las normas de las regiones autónomas fueran conformes con el Convenio $^{50}$. Por su parte, el profesor alemán Christian Tomuschat alabó cómo la transición española había facilitado la autodeterminación individual y colectiva ${ }^{51}$.

En las Observaciones finales del Comité se recoge la idea expresada por el agente español, que reafirma que el derecho de autodeterminación corresponde al pueblo español:

«Con referencia al artículo 1 del Pacto, puntualizó que el derecho correspondiente ya lo había ejercido el pueblo español al ratificar la Ley para la Reforma Política, que instauraba el régimen democrático y la nueva Constitución que lo organizaba. Junto a la proclamación de la «indisoluble unidad» de España, se reconocía y garantizaba el derecho a la autonomía de las nacionalidades $(. ..) \gg^{52}$.

IV.2. Tal y como recuerda el segundo informe sobre España, de 1985, de conformidad con sus reglas de trabajo, y, con anterioridad a su $24^{\circ}$ período de sesiones, el Comité encargó a un grupo de trabajo que analizara la infor-

49 «He would appreciate further clarification of paragraph 40 of the report (CCPR/CA/Add.l), which implied that since the Constitution recognized and guaranteed the right to autonomy of the nationalities and regions which made up the Spanish nation, it was impossible for any situation to arise in Spain which would involve actual discrimination against any of those nationalities and regions. It was not obvious to bim that the Constitution could make actual discrimination impossible in practice» (CCPR/C/SR.142 para. 24).

50 «Wat measures were envisaged to ensure that the laws and administrative decisions of self-governing regions would conform with the Covenant?» (CCPR/C/SR.142 para. 37). Esta observación fue recogida en dos parágrafos del el informe final (A/30/40 Supp, paras. 180-227), el $\mathrm{n}^{\circ} 185$ ( $\ll$ Refiriéndose a las medidas legislativas para institucionalizar la organización autonómica de las diversas regiones de España, algunos miembros pidieron más información acerca de las relaciones entre la autoridad regional y la nacional y, en particular, sobre las medidas encaminadas el asegurar que la autoridad regional actuara de conformidad con el Pacto») y el $\mathrm{n}^{\circ} 187$ ( «Se solicitó información sobre las consecuencias de la autonomía regional en el disfrute de los derechos humanos, sobre el lugar que ocupaba el Pacto en la legislación regional y sobre las medidas previstas para velar por que las leyes y decisiones administrativas de las regiones autónomas se ajustaban al Pacto»).

51 «two years after the beginning of the new era, one could not but admire the exemplary achievements of the Spanish people.. Recent events constituted a model case for what the drafters of the Covenant had hoped for: by providing for individual and collective self-determination, they had expected to promote conditions for stable political institutions whose noblest aims would be peace and justice, both internally and externally (CCPR/C/SR.142 para. 93).

52 A/30/40 supra, para. 208. 
mación hasta entonces presentada por el Gobierno de España con el objeto de identificar las materias que sería más útil debatir con los representantes del Estado informante. El grupo de trabajo preparó una lista de temas para ser examinados durante el diálogo con los representantes de España. La lista, completada por el Comité, fue comunicada a los representantes de España antes de su comparecencia y estaba acompañada de la debida explicación sobre el procedimiento a seguir. En particular, el Comité subrayó que la lista de temas no era exhaustiva y que los miembros podían plantear otras cuestiones y pedir a los representantes de España que comentaran los temas enumerados, sección por sección, y que respondieran a las eventuales preguntas de los miembros sobre otras cuestiones. El segundo informe presentado por España el 16 de julio de $1984^{53}$, fue examinado por el Comité en sus sesiones $585^{\mathrm{a}}$ a $589^{\mathrm{a}}$, celebradas el 2, el 3 y el 4 de abril de $1985^{54}$.

Según las Observaciones finales del Comitée ${ }^{55}$, se plantearon cuestiones sobre los aspectos externos e internos de la libre determinación. En relación al aspecto «interno», el informe dice que «varios miembros del Comité expresaron el deseo de recibir información sobre el grado real de autonomía de las Comunidades Autónomas de España ${ }^{56}$. El agente español, por su parte, contestó que «la Constitución española babía sido aprobada por abrumadora mayoría en un referéndum celebrado en 1978 y que su Gobierno opinaba que daba cumplimiento cabal a sus obligaciones respecto al derecho de libre determinación del pueblo español», precisando en relación a las Comunidades Autónomas que «eran entidades políticas auténticas, con organismos ejecutivos y legislativos propios que compartían responsabilidades con el Estado en sus esferas de competencia, definidas por la Constitución y el Tribunal Constitucional» $»^{57}$. Respecto al aspecto «externo» de la autodeterminación, los miembros del Comité también plantearon preguntas sobre la «posición de España respecto de la ocupación ilegal de Namibia, la situación del pueblo palestino y el régimen de apartheid imperante en Sudáfrica $»^{58}$, contestando el agente español que el Gobierno «se había pronunciado en favor de la libre determinación de los pueblos en todos los foros internacionales y había condenado expresamente y sin reservas las polí-

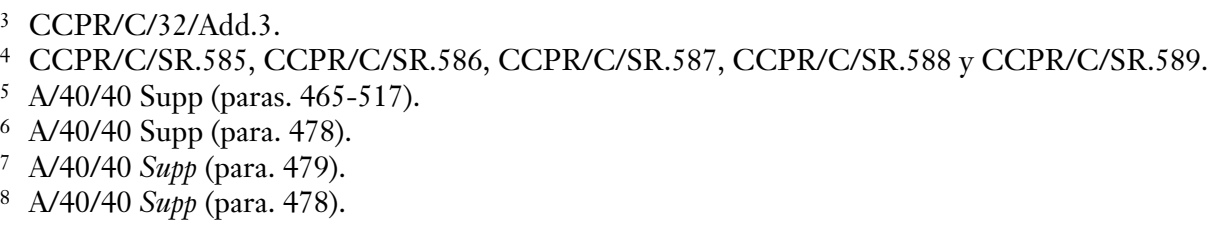


ticas dilatorias del Gobierno de Sudáfrica respecto a la cuestión de Namibia» añadiendo que España «había establecido las bases para la libre determinación del Sáhara Occidental y que seguiría apoyando los principios que lo habían movido a emprender esa acción ${ }^{59}$.

Según las «Observaciones finales», «los miembros del Comité expresaron su satisfacción por la protección cada vez más efectiva de los derechos humanos en España y por el carácter constructivo del debate celebrado durante el examen del segundo informe periódico de España» y que «el auténtico diálogo que se había entablado había aclarado muchas cuestiones que preocupaban a los miembros» ${ }^{60}$. Esto significa que se consideró satisfactoria la explicación de que el derecho de autodeterminación correspondiera al pueblo español. Es importante advertir que cuando se efectúa este segundo examen, en 1984-1985, la Constitución que proclamaba la soberanía nacional del pueblo español y excluía la invocación del derecho de autodeterminación para separar partes de España ya había sido aprobada. No sólo eso, sino que en esa fecha, el Tribunal Constitucional ya había declarado que la «autonomía» regional no es «soberanía» ${ }^{61}$.

IV.3. En efecto, parece que esta cuestión quedó aclarada cuando España presentó el 1 de junio de 1989 su tercer informe ${ }^{62}$, que fue examinado por el Comité el 29 y 30 de octubre de $1990^{63}$. Así lo revela el hecho de que en las Observaciones finales del Comité ${ }^{4}$, publicadas el 10 de octubre de 1991, no se contenga ninguna pregunta de los miembros del Comité sobre el grado de cumplimiento del art. 1 PIDCP. Es más, los miembros del Comité en sus Observaciones tras «expresar su satisfacción por el detallado informe presentado

\footnotetext{
$59 \mathrm{~A} / 40 / 40 \operatorname{Supp}($ para. 479).

60 A/40/40 Supp (para. 516).

61 STC 4/1981, de 2 de febrero (ponente: Gómez-Ferrer), FJ 3 («Ante todo, resulta claro que la autonomía hace referencia a un poder limitado. En efecto, autonomía no es soberanía -y aún este poder tiene sus límites-, y dado que cada organización territorial dotada de autonomía es una parte del todo, en ningún caso el principio de autonomía puede oponerse al de unidad, sino que es precisamente dentro de éste donde alcanza su verdadero sentido, como expresa el art. 2 de la Constitución»); STC 25/1981, de 14 de julio (ponente: Truyol), FJ 3 («Este Tribunal, en su Sentencia de 2 de febrero de 1981, tuvo ya ocasión de indicar que la autonomía reconocida, entre otros entes, a las Comunidades Autónomas por el art. 137 de la Constitución, se configura como un poder limitado, que no es soberanía»).

62 CCPR/C/58/Add. 1 y CCPR/C/58/Add.3.

63 CCPR/C/SR.1018, CCPR/C/SR.1019, CCPR/C/SR.1020, y CCPR/C/SR.1021.

64 A/46/40 Supp (paras. 142-185).
} 
por España», «agradecieron a la delegación del Estado parte su constructivo y fructífero diálogo con el Comité, que había permitido obtener de primera mano información acerca de los progresos de la España democrática» y afirmaron que «la mejora constante de la situación de los derechos humanos en España, debida especialmente al reforzamiento de la estructura jurídica y del aparato judicial, merecía respeto, y podía decirse con confianza que España seguía avanzando en todos los frentes» ${ }^{65}$. Es más, entre los problemas que, no obstante, seguían existiendo para algunos miembros del Comité no se encontraba ninguna referencia a la falta de cumplimiento del art. 1 PIDCP $^{66}$.

Por su parte, en su cuarto informe ${ }^{67}$, presentado el 2 de junio de 1994, el Gobierno español en relación con el artículo 1 afirma que «el proceso de creación del llamado «Estado de las autonomías», consecuencia de la Constitución de 1978, puede darse por prácticamente concluido, e iniciada una fase que cabe denominar de perfeccionamiento o profundización del sistema autonómico» ${ }^{68}$. Durante el examen del Informe, en las sesiones celebradas los días 20 y 21 de marzo de $1996^{69}$, ningún miembro del Comité cuestionó la falta de respeto del art. 1 PIDCP. Y en las «Observaciones finales» ${ }^{70}$, publicadas el 3 de abril de 1996, no se encuentra ninguna relativa a un hipotético incumplimiento del art. 1 PIDCP.

Algo parecido ocurre con ocasión del quinto informe, presentado el 9 de febrero de $2007^{71}$ donde simplemente se advierte que «El llamado «Estado de las autonomías», consecuencia del reconocimiento en el artículo 2 de la Constitución Española de 1978 del derecho a la autonomía de las nacionalidades y regiones que la integran, se balla plenamente implantado y en fase de profundización $\gg^{72}$, declaración prácticamente igual a la hecha con ocasión del sexto informe, presentado el 27 de diciembre de $2012^{73}$. En este sentido, ni en las «listas» elaborada por el Comité de las «cuestiones» relativas al quinto ${ }^{74}$ y al sexto ${ }^{75}$ informes perió-

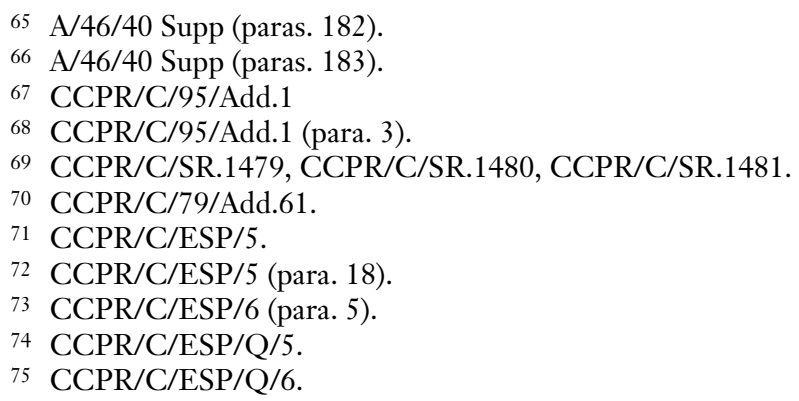


dicos de España», ni en ninguna, repito, en ninguna de las «informaciones» enviadas por ONGs (algunas de clara inspiración separatista) se denuncia la vulneración de este supuesto derecho a la autodeterminación para separarse de España. Es lógico, por ello, que en las Observaciones finales al quinto ${ }^{76}$ y sexto ${ }^{77}$ informes de España no haya ninguna mención a la posibilidad, que el ordenamiento español niega, de reconocer el «derecho de autodeterminación» a una parte de España para separarse y, de hecho, en el diálogo de España con el Comité ningún miembro de éste planteo cuestiones al respecto.

El asunto es tanto más relevante en cuanto que el diálogo de España con el Comité de Derechos Humanos acerca de sus informes quinto y sexto se lleva a cabo cuando ya se ha desencadenado una ofensiva secesionista que fue frenada por el Tribunal Constitucional.

Así, por un lado, el diálogo con el Comité sobre el quinto informe se lleva a cabo en noviembre de 2008 y las Observaciones finales al quinto informe se elaboran el 5 de febrero de 2009, cuando ya se había desencadenado una ofensiva secesionista en la región vasca. El Parlamento regional vasco había aprobado en junio de 2008 la llamada «ley de consulta vasca» ${ }^{78}$ que contenía una pregunta que suponía atribuir un derecho de autodeterminación al «pueblo vasco» ${ }^{79}$, y que el Tribunal Constitucional había declarado inconstitucionalidad en septiembre de $2008^{80}$.

Por otro lado, el diálogo sobre el sexto informe de España se lleva a cabo en 2015, elaborándose el 23 de julio de 2015 las Observaciones finales del Comité (que se hicieron públicas el 16 de agosto de ese año). En esas fechas, como es notorio, ya se había iniciado el «prusés» separatista catalanista. La sentencia del Tribunal Constitucional examinando la constitucionalidad del nuevo Estatuto de autonomía de $2006^{81}$ y declarando que el atributo de «nación» a Cataluña carecía de efectos jurídicos es de junio de $2010^{82}$. La

$76 \mathrm{CCPR} / \mathrm{C} / \mathrm{ESP} / \mathrm{CO} / 5$.

$77 \mathrm{CCPR} / \mathrm{C} / \mathrm{ESP} / \mathrm{CO} / 6$.

78 Ley del Parlamento Vasco 9/2008, de 27 de junio, «de convocatoria y regulación de una consulta popular al objeto de recabar la opinión ciudadana en la Comunidad Autónoma del País Vasco sobre la apertura de un proceso de negociación para alcanzar la paz y la normalización política».

79 «iEstá Usted de acuerdo en que los partidos vascos, sin exclusiones, inicien un proceso de negociación para alcanzar un Acuerdo Democrático sobre el ejercicio del derecho a decidir del Pueblo Vasco, y que dicho Acuerdo sea sometido a referéndum antes de que finalice el año 2010?»

80 STC 103/2008, de 11 de septiembre (ponente: Jiménez).

81 Ley Orgánica 6/2006, de 19 de julio, de reforma (sic) del Estatuto de Autonomía de Cataluña.

82 STC 31/2010, de 28 de junio (ponente: Casas), FJ 12. 
«declaración de soberanía» es de 24 de enero de $2013^{83}$ y en esas fechas ya era conocida la resolución del Tribunal Constitucional, de 25 de marzo de $2014^{84}$, que anuló dicha «declaración», por tanto casi un año y medio antes de que el Comité publicara esas Observaciones finales. Dichas Observaciones finales también son posteriores a la convocatoria de la «consulta» promovida por el gobierno regional catalán (presidido entonces por Artur Mas y Gavarró) el día 9 de noviembre de 2014 que implicaba un ejercicio de autodeterminación para separarse de España ${ }^{85}$ y que fue anulada por el Tribunal Constitucional en sentencia de junio de $2015^{86}$.

La doctrina del Comité de Derechos Humanos nunca ha avalado este derecho para romper la integridad territorial de un pueblo, pero sí lo ha atribuido a un pueblo ocupado o colonizado por otro. Pero, por si hubiera dudas sobre el significado de esta omisión al derecho de autodeterminación para separar partes de España, considérese como contraste la doctrina del Comité de Derechos $\mathrm{Hu}-$ manos respecto a Marruecos. Ya en sus Observaciones finales al informe inicial de Marruecos (presentado el 9 de febrero de 1981), el Comité dijo esto:

«En relación con el artículo 1 del Pacto, se hizo notar que el informe no contenía ningún dato sobre la libre determinación del territorio conocido con el nombre de Sahara accidental, y se preguntó qué medidas se habían tornado para que la población de ese territorio pudiera decidir libremente su situación política y configurar, libremente también, su desarrollo económico social y cultural ${ }^{87}$.

Algo parecido ocurrió con las Observaciones finales del Comité al los demás informes presentados por Marruecos, donde este país omite cualquier referencia al Sahara Occidental, pese a lo cual el Comité le exige que respete el derecho de autodeterminación de ese país. Así ocurre respecto al segundo informe de Marruecos (presentado el 22 de marzo de 1990) ${ }^{88}$, el tercer infor-

83 Resolución 5/X del Parlamento de Cataluña por la que se aprueba la Declaración de soberanía y el derecho a decidir del pueblo de Cataluña, en Butlletí Oficial del Parlament de Catalunya $\mathrm{n}^{\circ} 13 / 10,24-\mathrm{I}-2013$, p. 3 ss.

84 STC 42/2014, de 25 de marzo (ponente: Asúa).

85 Las preguntas en esa «consulta» eran: «iQuiere que Cataluña se convierta en un Estado?»; «iQuiere que este Estado sea independiente?».

86 STC 138/2015, de 11 de junio (ponente: Asúa).

87 A/37/40 Supp (para. 136).

88 A/46/40 Supp, para. 238 («algunos miembros del Comité pidieron al representante que formulara observaciones sobre loa problemas relativos a la libre determinación en el Sábara Occidental en el marco de las obligaciones asumidas por el Reino de Marruecos en virtud del párrafo 3 del artículo 1 del Pacto»). 
me que Marruecos (presentado el 20 de julio de 1993) ${ }^{89}$, el cuarto informe (presentado el 15 de octubre de 1997) ${ }^{90}$, el quinto informe (presentado el 4 de marzo de 2004) ${ }^{91}$. Sólo en su sexto informe (presentado el 7 de julio de 2015$)^{92}$, Marruecos hace una alusión a la autodeterminación de la «región del Sahara» (sic), donde dice que «Desde tiempos inmemoriales (sic), el Sábara (sic) ba formado parte integrante del Reino de Marruecos» ${ }^{93}$, alegación que no convenció al Comité que en sus Observaciones finales de 1 de diciembre de 2016 volvió a conminar a Marruecos que «el pueblo del Sáhara Occidental pueda ejercer el derecho a la libre determinación» ${ }^{94}$.

\section{Conclusiones}

Tras todo lo expuesto pueden extraerse algunas conclusiones:

$1^{\mathrm{a}}$. El «derecho a la autodeterminación», internacionalmente reconocido como derecho a formar un Estado independiente sólo se predica de los pue-

89 CCPR/C/79/Add.44, para. 8 («Le preocupa al Comité el papel de Marruecos en lo que respecta a la persistencia de los problemas relacionados con la autodeterminación en el Sábara Occidental»).

90 CCPR/C/79/Add.113, para. 9 («El Comité sigue preocupado por el avance muy lento de los preparativos para un referendo en el Sábara Occidental sobre la cuestión de la libre determinación»).

91 CCPR/CO/82/MAR, para. 8 («El Comité sigue preocupado por la ausencia de progresos en la cuestión de la10aplicación de la libre determinación del pueblo del Sábara Occidental (art. 1 del Pacto).»).

$92 \mathrm{CCPR} / \mathrm{C} / \mathrm{MAR} / 6$

93 CCPR/C/MAR/6, para. 31.

$94 \mathrm{CCPR} / \mathrm{C} / \mathrm{MAR} / \mathrm{CO} / 6$, paras. 9 y 10 :

«9. El Comité toma nota de la iniciativa de Marruecos para la negociación de un estatuto de autonomía de la región del Sábara Occidental, y de las informaciones complementarias presentadas por el Estado parte, pero sigue preocupado por: a) los limitados progresos logrados en relación con la cuestión de la libre determinación del pueblo del Sábara Occidental; b) las informaciones según las cuales el Estado parte no adopta todas las medidas necesarias para consultar al pueblo del Sábara Occidental respecto de la explotación de los recursos naturales en dicha región; y c) la presencia de la berma (muro de arena), que limita la libertad de circulación del pueblo del Sáhara Occidental por causa del escaso número de puntos de acceso abiertos a los civiles, y la presencia de minas terrestres y otros restos explosivos de guerra a lo largo de dicha berma, que ponen en peligro la vida y la seguridad de las poblaciones que viven en sus proximidades (arts. 1, 6 y 12).

10. El Estado parte debe: a) proseguir e intensificar la labor realizada como parte del proceso de negociación sobre el estatuto del Sábara Occidental, que se lleva a cabo bajo los auspicios del Secretario General de las Naciones Unidas, a fin de que el pueblo del Sábara Occidental pueda ejercer el derecho a la libre determinación; b) reforzar el proceso de consulta con el pueblo del Sábara Occidental para obtener su consentimiento previo, libre e informado para la realización de proyectos de desarrollo y operaciones extractivas; y c) tomar las medidas necesarias para que el pueblo del Sáhara Occidental pueda circular libremente y en condiciones de seguridad a ambos lados de la berma, y continuar el programa de desminado a lo largo de esta e indemnizar a las víctimas». 
blos de los Estados ya constituidos y de los pueblos sometidos a dominación colonial, pero no de partes de un Estado ya constituido.

$2^{a}$. Los intentos de consagrar, en el Derecho español, un derecho de secesión de una parte de España, derivándolo de un reconocimiento del «derecho a la autodeterminación» incluido en el PIDCP, han sido rechazados. No fueron admitidos en el texto constitucional y los intentos de introducirlo por algunos parlamentos regionales han sido anulados por el Tribunal Constitucional.

$3^{\mathrm{a}}$. Aunque el PIDCP fue ratificado en 1977, antes de elaborarse y aprobarse la Constitución de 1978, el Tribunal Constitucional español ha interpretado que el mismo es compatible con la Constitución pues no reconoce a partes de España un «derecho a la autodeterminación» para separarse de la misma quebrando la unidad de la soberanía que posee un titular único, la nación española.

$4^{\mathrm{a}}$. La doctrina y la práctica del Comité de Derechos Humanos al examinar los sucesivos informes presentados por el Reino de España (seis hasta el momento) sobre el grado de cumplimiento del PIDCP revelan que en ningún caso el Comité de Derechos Humanos ha avalado la tesis de que, en virtud del citado Pacto, partes de España tengan derecho a separarse rompiendo la unidad nacional. 